\title{
The female partners' perspective on vasectomy in the central region of Ghana
}

\author{
Joseph A. Adu' ${ }^{\text {, Eugene K. M. Darteh }}{ }^{2}$, Derek A. Tuoyire ${ }^{3}$ and Sebastian Eliason ${ }^{3}$ \\ Ghana Med J 2018; 52(4):177-182 doi: http://dx.doi.org/10.4314/gmj.v52i4.3
}

\author{
${ }^{1}$ Department of Obstetrics and Gynaecology, School of Medical Sciences, University of Cape Coast, Ghana, \\ ${ }^{2}$ Department of Population and Health, University of Cape Coast, Ghana \\ ${ }^{3}$ Department of Community Medicine, School of Medical Sciences, University of Cape Coast, Ghana
}

\author{
Corresponding author: Dr Sebastian Eliason \\ E-mail: s.eliason@uccsms.edu.gh \\ Conflict of interest: None declared
}

\section{SUMMARY}

Background: Vasectomy is one of the safest and inexpensive modern contraceptive methods but it remains relatively 'invisible' in Ghana. Support of women may be a significant incentive in influencing their partners to adopt vasectomy.

Objective: To examine the perspectives of women on vasectomy as a contraceptive option.

Materials and Methods: A cross-sectional survey was conducted among 298 women accessing long-term or permanent family planning methods at health facilities in three selected districts in the Central Region of Ghana. Pearson's Chi-square was used to test associations between variables and the attitudes of women towards vasectomy. A p-value of less than 0.05 was considered to be statistically significant

Results: Awareness of vasectomy was low (32\%). About $66 \%$ of the women who became aware of vasectomy during the study would prefer their partners to go for vasectomy compared with $50 \%$ of those who were aware prior to the study. Women who would either not prefer vasectomy or support their partner's choice of vasectomy cited fear of impotency $(39.6 \%)$. There was a statistically significant association $(\mathrm{p}<0.05)$ between ethnicity, previous contraceptive use, awareness of male methods, and preference for vasectomy instead of bilateral tubal ligation (BTL). A statistically significant association $(\mathrm{p}<0.05)$ was also found between age of participant, duration of marriage, religious affiliation, and the willingness of women to support their partner's choice of vasectomy.

Conclusion: There is, therefore, the need for the involvement of women in the promotion of vasectomy through vigorous publicity and education.

Funding: By authors

Keywords: vasectomy, tubal, contraceptive agents, Ghana, sterilization

\section{INTRODUCTION}

In the past 40 years, family-planning programmes have played a major part in raising the prevalence of contraceptive practice from less than $10 \%$ to $60 \%$ and reducing fertility in developing countries from six to about three births per woman. ${ }^{1}$ Effective family planning also has the potential to reduce poverty and hunger, avert $32 \%$ of all maternal deaths and nearly $10 \%$ of childhood deaths and contribute to women's empowerment, achievement of universal primary schooling, and long-term environmental sustainability. ${ }^{1}$ However, in half the 75 larger low-income and lower-middle income countries (mainly in Africa), contraceptive practice remains low and fertility, population growth, and unmet need for family planning are high. ${ }^{1}$ Family planning programs and methods have over the decades focused more on women.

Short-term and reversible methods, such as the pill, injectable and male condom, are more common than other methods in Africa and Europe, whereas long-acting or permanent methods, such as sterilization, implants and the IUD, are more common in Asia and Northern America. $^{2}$ Globally, female sterilization, also known as bilateral tubal ligation (BTL) is currently the most widely used long-term contraceptive method, and it is projected to remain so over the next decade.,3 Family-planning methods vary greatly in terms of effectiveness and are usually divided into three categories: most effective, effective, and less effective. ${ }^{4}$ Even the least effective method is considerably better than using nothing, since $85 \%$ of couples will become pregnant within one year without contraception. ${ }^{1}$ In terms of cost-effectiveness of pregnancies prevented, sterilization (male and female) and intrauterine devices are the best value. ${ }^{5}$

Though vasectomy (male sterilization) is safer, simpler, less expensive, and equally as effective as female sterilization, it is the least known, least understood, least used and a much less preferred option in African countries. ${ }^{6,7}$ 
As in many other countries, vasectomy in Ghana is relatively an "invisible" family planning method and even more so compared with BTL. Currently, the prevalence of vasectomy as a family planning method is nearly ten times less than BTL. ${ }^{8}$ Perhaps this is in part as a result of the low awareness of vasectomy compared with other family planning methods among both men and women in Ghana.

For example, although about 7 in 10 women are aware about female sterilisation, just about one-third are aware about male sterilization or vasectomy. ${ }^{9}$ In addition, those who are aware of vasectomy frequently have incomplete or incorrect information about it. ${ }^{10}$ Extant research points the poor utilisation of vasectomy in Ghana as well as many other affected countries to four key factors - a lack of awareness of vasectomy as a contraceptive option, myths and rumors about vasectomy, a lack of access to services, and indifference and bias on the part of providers. ${ }^{10,11}$ Nevertheless, in countries where vasectomy is more popular than female sterilization, one of the major reasons cited is women's encouragement to their partners to undergo vasectomy since it is easier than female sterilisation $^{12}$. Studies have confirmed that women often play an active and influential role in men's decisions to have a vasectomy. ${ }^{3}$ Men are more likely to consider vasectomy if their partners favour it. Considering the significance of women in influencing their partners to adopt vasectomy as a family planning option, the study examined the perspectives of women on vasectomy as a contraceptive option.

\section{METHODS}

\section{Study design}

This was a cross sectional survey of women accessing long-term or permanent family planning methods in health facilities in the central region. It was conducted over a period of 6 months from November 2014 to April 2015.

\section{Study Area}

The population of the central region was estimated at $2,413,050$ for the year 2013 with an annual growth rate of $3.1 \%{ }^{13}$ About $63 \%$ of the region is rural with a population density of about 215 inhabitants per square kilometer. ${ }^{9}$ Although, the central region's total fertility rate (TFR) had decreased from 5.4 to 4.7 from 2008 to 2013, it remains high, with four births per every 100 adolescents in the region which is among the highest compared to the other regions. ${ }^{8,9}$ The region also recorded a contraceptive prevalence rate (CPR), among currently married women, of $27.5 \%$ in 2014 , making it the regions with the highest CPR in the country. ${ }^{9}$

Three districts were selected using systematic random sampling from the twenty districts in the central region. The three districts were Twifo-Heman-Lower-Denkyira (population of 116,874),
Asikuma-Odoben-Brakwa (population of 112,706) and Komenda-Edina-Eguafo-Abirem (population of 161,208). ${ }^{8}$ In each of the three districts, all health facilities that offered long-term and permanent family planning methods (LAPM) were identified and the top three facilities offering the highest number of LAPMs were purposively selected. Study population was all women seeking long term or permanent family planning methods in the selected health facilities.

\section{Sampling}

Six months prior to the study (May - October 2014), a total of 1,310 women had attended the 9 health facilities for long-term or permanent contraceptive methods (See Table 1). The assumption was that similar numbers would present themselves during the study period. For a finite population, the sample size $\mathrm{S}_{\mathrm{T}}$ for the study was estimated by the formula $\mathrm{S}_{\mathrm{T}}=\mathrm{A} /[1+(\mathrm{A}-1) / \mathrm{T}]$, where $\mathrm{A}$ is given by $\left[\mathrm{Z}^{2 *} \mathrm{P} *(1-\mathrm{P})\right] / \mathrm{C}^{2} ; \mathrm{T}=$ estimated target population of women visiting the nine selected health facilities for long-term or permanent contraceptive methods within the study period $(1,310) ; Z=Z$ value $(1.96$ for $95 \%$ confidence); $\mathrm{P}=$ Proportion of women who would endorse their husband's use of vasectomy $(50 \%)$; and $\mathrm{C}=$ margin of error (5\%). Therefore, $\mathrm{A}=\left[1.96^{2}(0.5)(0.5)\right] / 0.05^{2}$ $=384 ; \mathrm{S}_{\mathrm{T}}=384 /[1+(384-1) / 1310]=298$.

Table 1 Health facilities, number of women assessing LAPM and number of women recruited into study

\begin{tabular}{|c|c|c|c|}
\hline Districts & Health Facility & $\begin{array}{l}\text { No. of women } \\
\text { assessing } \\
\text { LAPM ser- } \\
\text { vices }\end{array}$ & $\begin{array}{lr}\text { No. } & \text { of } \\
\text { women } & \text { re- } \\
\text { cruited into } \\
\text { study }\end{array}$ \\
\hline \multirow{3}{*}{$\begin{array}{l}\text { Twifo-Heman- } \\
\text { Lower-Denkyira }\end{array}$} & Jukwa & 130 & 29 \\
\hline & Heman & 202 & 46 \\
\hline & Morkwaa & 106 & 24 \\
\hline \multirow{3}{*}{$\begin{array}{l}\text { Komenda-Edina- } \\
\text { Eguafo-Abirem }\end{array}$} & Komenda & 145 & 33 \\
\hline & Elmina & 130 & 30 \\
\hline & Abirem Agona & 161 & 37 \\
\hline \multirow{4}{*}{$\begin{array}{l}\text { Asikuma-Odo- } \\
\text { ben-Brakwa }\end{array}$} & Asikuma $\mathrm{RCH}$ & 190 & 43 \\
\hline & Odoben & 105 & 24 \\
\hline & Brakwa & 141 & 32 \\
\hline & Total & 1310 & 298 \\
\hline
\end{tabular}

Source: Field data 2014 and 2015

By probability proportional to size, the numbers of women recruited from each of the nine health facilities were as shown in Table 1 . All the 298 women were recruited by systematic random sampling. They were recruited if they consented to be part of the study.

\section{Data collection}

Each participant was taken through a 10 to 15 -minute face-to-face interview between November 2014 and April 2015. The interviews were conducted by the lead author and two nurses who were trained for the purpose of the study. A structured questionnaire made up of two main sections was the instrument used for data collection. The first section sought to obtain background socio-demographic information such as; age, educational status, marital status, ethnicity and religion. 
The second part explored their contraceptive behaviour, as well as their awareness of and attitude towards vasectomy. Prior to the commencement of data collection, the instrument was pre-tested at the Adisadel Health centre, which has similar characteristics as the study sites. The pre-testing was useful in ascertaining the appropriateness of the questions for the purpose of the study. All necessary adjustments and modifications to the instrument were made following pre-testing to increase the chances of obtaining valid and reliable responses.

Awareness among women was mainly observed by determining how many of them had heard of vasectomy ("a family planning operation for men to avoid having any more children"). Attitude towards vasectomy was determined by asking the questions: "would you prefer your partner does vasectomy instead of you going for sterilization?" and "if your partner decides to undergo the operation (vasectomy), would you support the idea?" To avoid misunderstanding of the issues, vasectomy as a contraceptive method was well explained to all study participants before the questions on attitude were posed. Further probing was done for women who would not favour vasectomy or support their partner's decision to use vasectomy in order to understand their reasons.

\section{Data processing and analysis}

STATA version 14.0 software was used for data input, cleaning and analyses. Descriptive analyses were mainly conducted, beginning with a univariate analysis of the women who participated in the study. Next, bivariate analyses were conducted to examine the association between the characteristics of the women and their preference for vasectomy, as well as their willingness to support their partner's decision to undergo vasectomy. Row percentages and the Pearson's Chi-square test were employed in describing the associations between the characteristics of the women and their attitude - preference for vasectomy and willingness to support their partner's choice of vasectomy - of women towards vasectomy. A p-value of less than 0.05 was considered to be statistically significant.

\section{Ethical considerations}

Ethical approval for the study was obtained from the University of Cape Coast Institutional Review Board (REF: UCCIRB/CES/2017/26), while permission was obtained from the management of the selected health facilities. Before conducting each interview the purposes of the study, possible risks and benefits and the voluntary nature of participation were explained. The participants were assured of privacy and confidentiality, and both verbal and written consents were obtained.

\section{RESULTS}

\section{Sample Characteristics}

As Indicated in Table 2, about four in ten of the study participants were in the 15 to 24 year age group.
All the participants had some level of formal education, with more than half $(67.8 \%)$ having had middle/JHS education. Majority $(73.8 \%)$ of the participants were married with average marriage duration of 9 years. The sample was predominantly Christian, with those belonging to Charismatic denominations forming the majority $(45.5 \%)$.

Table 2 Characteristics of the women

\begin{tabular}{|c|c|}
\hline Characteristics & N (\%) \\
\hline \multicolumn{2}{|l|}{ Age } \\
\hline $15-24$ & $115(38.7)$ \\
\hline $25-34$ & $108(36.4)$ \\
\hline $35+$ & 74 (24.9) \\
\hline \multicolumn{2}{|c|}{ Mean $=28.4(\mathrm{SD}=7.6)$} \\
\hline \multicolumn{2}{|c|}{ Education } \\
\hline Primary & $61(26.2)$ \\
\hline Middle/JHS & $158(67.8)$ \\
\hline Secondary + & $14(6.0)$ \\
\hline \multicolumn{2}{|l|}{ Marital status } \\
\hline Single & $78(26.2)$ \\
\hline Married & $220(73.8)$ \\
\hline \multicolumn{2}{|l|}{ Marriage duration } \\
\hline 0-9yrs & $125(58.4)$ \\
\hline 10-19yrs & $65(30.4)$ \\
\hline $20+$ & $24(11.2)$ \\
\hline \multicolumn{2}{|c|}{ Mean $=9.0($ SD $=6.7)$} \\
\hline \multicolumn{2}{|c|}{ Religion } \\
\hline Orthodox & $62(21.4)$ \\
\hline Charismatic & $132(45.5)$ \\
\hline Spiritual church & $73(25.2)$ \\
\hline None/others & $23(7.9)$ \\
\hline \multicolumn{2}{|l|}{ Ethnicity } \\
\hline Akan & $249(85.6)$ \\
\hline Ga/Adangbe & $15(5.2)$ \\
\hline Ewe & $14(4.8)$ \\
\hline Others & $13(4.4)$ \\
\hline \multicolumn{2}{|c|}{ Previous contraception } \\
\hline No & $155(53.1)$ \\
\hline Yes & $137(46.9)$ \\
\hline \multicolumn{2}{|c|}{ Awareness of male methods } \\
\hline No & $133(45.2)$ \\
\hline Yes & $161(54.8)$ \\
\hline
\end{tabular}

Source: Field data 2015

Note: $\mathrm{N}$ may be less than 298 in some cases due to missing information

\section{Awareness of vasectomy}

Generally, awareness of vasectomy as a contraceptive option prior to the study was found to be low (32\%). Four in ten women who had heard of vasectomy knew a health facility where the procedure could be done. In addition, $14 \%$ of these women had ever had partners who had undergone vasectomy.

A greater proportion (66.3\%) of the women who became aware of vasectomy during the study would prefer their partners to go for vasectomy compared with $50 \%$ of those aware prior to the study. The proportions of women who would support their partner's choice of vasectomy, however, did not vary much between those who became aware during the study $(79.8 \%)$ and those aware prior to the study $(77.4 \%)$. 
Women who would either not prefer vasectomy or support their partner's choice of vasectomy gave the following reasons; afraid of side effects such as impotency or sexual weakness $(39.6 \%)$, would choose BTL instead $(25.0 \%)$, might decide to have more children later $(18.7 \%)$ and no specific reason $(16.7 \%)$.

Table 3 Associations between characteristics of women and preference for vasectomy

\begin{tabular}{|c|c|c|c|c|}
\hline Characteristics & N (298) & $\begin{array}{l}\begin{array}{l}\text { Prefer part- } \\
\text { ner's vasec- } \\
\text { tomy to BTL } \\
(\%)\end{array} \\
\end{array}$ & $\mathrm{X}^{2}$ & $\begin{array}{l}P \text { - } \\
\text { value }\end{array}$ \\
\hline \multicolumn{5}{|l|}{ Age } \\
\hline $15-24$ & 115 & 61.9 & 0.49 & 0.784 \\
\hline 25-34 & 108 & 58.8 & & \\
\hline $35+$ & 74 & 63.8 & & \\
\hline \multicolumn{5}{|l|}{ Education } \\
\hline Primary & 61 & 63.9 & 0.67 & 0.718 \\
\hline Middle/JHS & 158 & 58.1 & & \\
\hline Secondary + & 14 & 57.1 & & \\
\hline \multicolumn{5}{|l|}{ Marital status } \\
\hline Single & 78 & 53.8 & 2.35 & 0.125 \\
\hline Married & 220 & 63.7 & & \\
\hline \multicolumn{5}{|l|}{ Marriage duration } \\
\hline 0-9yrs & 125 & 63.9 & 0.56 & 0.757 \\
\hline 10-19yrs & 65 & 60.9 & & \\
\hline $20+$ & 24 & 69.6 & & \\
\hline \multicolumn{5}{|l|}{ Religion } \\
\hline Orthodox & 62 & 55.7 & 1.35 & 0.715 \\
\hline Charismatic & 132 & 63.8 & & \\
\hline Spiritual church & 73 & 61.6 & & \\
\hline None/others & 23 & 56.5 & & \\
\hline \multicolumn{5}{|l|}{ Ethnicity } \\
\hline Akan & 249 & 64.4 & 15.80 & $0.001 *$ \\
\hline Ga/Adangbe & 15 & 13.3 & & \\
\hline Ewe & 14 & 61.5 & & \\
\hline Others & 13 & 53.8 & & \\
\hline \multicolumn{5}{|l|}{$\begin{array}{l}\text { Previous contra- } \\
\text { ception }\end{array}$} \\
\hline No & 155 & 66.7 & 4.03 & $0.045^{*}$ \\
\hline Yes & 137 & 55.2 & & \\
\hline \multicolumn{5}{|l|}{$\begin{array}{l}\text { Awareness of male } \\
\text { methods }\end{array}$} \\
\hline No & 133 & 67.2 & 4.21 & $0.040 *$ \\
\hline Yes & 161 & 55.4 & & \\
\hline
\end{tabular}

Preference for vasectomy by selected background factors

The results indicated (Table 3 ) a statistically significant relationship $(\mathrm{p}<0.05)$ between ethnicity, previous contraceptive use, awareness of vasectomy, and women's preference for partners to undergo vasectomy rather than them going for BTL. Compared with younger age groups, women aged 35 years and older $(63.8 \%)$ were more in favour of their partners going for vasectomy. More of those with primary (63.9\%) education preferred the use of vasectomy than those with secondary or higher (57.1\%) education. Although, preference for vasectomy was higher among married women (63.7\%), it differed with duration of marriage.
Those who had been married for 20 or more years $(69.6 \%)$ were likely to prefer vasectomy to BTL. In terms of religion, more women affiliated to Charismatic $(63.8 \%)$ than other churches preferred vasectomy to BTL. Majority of Akans (64.4\%) preferred vasectomy over BTL, followed by the Ewes (61.5\%). Women who had no history $(66.7 \%)$ of contraception and those not aware (67.2\%) of any male method were more likely to prefer vasectomy compared with their counterparts who had previously (55.2\%) used contraception and those who were aware $(55.4 \%)$ of male methods, respectively.

Table 4 Associations between characteristics of women and willingness to support partner's choice of vasectomy

\begin{tabular}{|c|c|c|c|c|}
\hline Characteristics & $\begin{array}{l}N \\
(298)\end{array}$ & $\begin{array}{l}\text { Support } \\
\text { partner's } \\
\text { vasectomy } \\
\text { decision } \\
(\%)\end{array}$ & $\mathbf{X}^{2}$ & $\begin{array}{l}P \text { - } \\
\text { value }\end{array}$ \\
\hline \multicolumn{5}{|l|}{ Age } \\
\hline $15-24$ & 115 & 72.2 & $10.12 *$ & 0.006 \\
\hline $25-34$ & 108 & 79.4 & & \\
\hline $35+$ & 74 & 91.6 & & \\
\hline \multicolumn{5}{|l|}{ Education } \\
\hline Primary & 61 & 88.3 & 5.51 & 0.064 \\
\hline Middle/JHS & 158 & 73.9 & & \\
\hline Secondary + & 14 & 71.4 & & \\
\hline \multicolumn{5}{|l|}{ Marital status } \\
\hline Single & 78 & 75.6 & 0.84 & 0.359 \\
\hline Married & 220 & 80.6 & & \\
\hline \multicolumn{5}{|l|}{ Marriage duration } \\
\hline 0-9yrs & 125 & 73.9 & 6.15 & $0.046^{*}$ \\
\hline $10-19 y r s$ & 65 & 89.2 & & \\
\hline $20+$ & 24 & 81.8 & & \\
\hline \multicolumn{5}{|l|}{ Religion } \\
\hline Orthodox & 62 & 75.8 & 9.49 & $0.023 *$ \\
\hline Charismatic & 132 & 85.5 & & \\
\hline Spiritual church & 73 & 75.3 & & \\
\hline None/others & 23 & 59.1 & & \\
\hline \multicolumn{5}{|l|}{ Ethnicity } \\
\hline Akan & 249 & 78.1 & 0.74 & 0.863 \\
\hline Ga/Adangbe & 15 & 80.0 & & \\
\hline Ewe & 14 & 85.7 & & \\
\hline Others & 13 & 84.6 & & \\
\hline \multicolumn{5}{|l|}{$\begin{array}{l}\text { Previous contra- } \\
\text { ception }\end{array}$} \\
\hline No & 155 & 77.9 & 0.21 & 0.643 \\
\hline Yes & 137 & 80.2 & & \\
\hline \multicolumn{5}{|c|}{ Awareness of male methods } \\
\hline No & 133 & 79.4 & 0.02 & 0.894 \\
\hline Yes & 161 & 78.8 & & \\
\hline
\end{tabular}

\section{Support for partner's choice of vasectomy by selected background factors}

As shown in Table 4, age, duration of marriage and religion were found to be significantly $(\mathrm{p}<0.05)$ associated with the willingness of women to support their partner's decision to opt for vasectomy. Nine-in-ten women aged 35 years and older, compared with seven-in-ten women in the other age groups would support their partner's decision to opt for vasectomy. 
Support for partner's choice of vasectomy appeared to reduce with level of education. For instance, while $88.3 \%$ of women would offer their support to the partners, $71.4 \%$ of their counterparts with secondary or higher education would do same. A greater proportion of married $(80.6 \%)$, particularly those in their second decade $(89.2 \%)$ of marriage would support their partner's choice of vasectomy. More than two fifth of those affiliated to Charismatic churches and those belonging to the Ewe ethnic group would support their partner if he opted for vasectomy. While support for a partner's decision to go for vasectomy was higher for women with a history of contraception (80.2\%), the proportions did not vary much from those who were aware of male contraceptive methods $(78.8 \%)$.

\section{DISCUSSION}

The study investigated whether women in the Central region of Ghana would prefer to have their partners undergo vasectomy rather than them undergoing BTL and the willingness of such women to support their partners decision to opt for vasectomy.

This study found awareness of vasectomy as a contraceptive option prior to the study to be low (32\%) compared with prior studies, which reported very high awareness. This finding is consistent with earlier studies among women attending antenatal clinic in a tertiary hospital in India $^{3}$ and in an urban population of women in Maharashtra. ${ }^{14}$ The low awareness of vasectomy prior to the study could be as a result of the fact that vasectomy is a male contraceptive method hence women were not very much exposed to it.

In their study, Soaji et al., demonstrated a high disapproval rate of vasectomy among the women $(66.5 \%)^{3}$. By contrast, about seven in ten women in the current study would support their partner's choice of vasectomy as a contraceptive method. This finding presents an opportunity for involving women in advocacy efforts to scale up the uptake of vasectomy by men. The women who expressed some reservations about supporting their partners to opt for vasectomy mainly suggested fear of side effects such as impotency or sexual weakness. Similar culturally biased misconceptions about vasectomy have been reported in prior studies ${ }^{3,6}$.

A statistically significant relationship was established between ethnicity, previous contraceptive use, awareness of vasectomy, and women's preference for partners to undergo vasectomy rather than them going for BTL. Both history of contraceptive use and awareness of vasectomy suggest that women's prior appreciation of the importance of family planning methods might have influenced their preference for vasectomy as a choice for their partners rather than them opting for BTL.
The study found age, marital duration and religion to be significant factors associated with women supporting the partners' decision to use vasectomy as a male contraceptive method. Compared with younger age groups, women aged 35 years and older were more likely to support their partner's decision to opt for vasectomy. Similarly, those who had been married for 20 or more years were more likely to support their partner's decision to opt for vasectomy. This finding could be linked with the fact that these older women and those with longer durations of marriage might have attained their desired number of children and hence are seeking to meet their need for contraception through vasectomy. The finding of a significant relationship between religion and vasectomy is consistent with finding in a study by Brune et al.,.$^{6}$

Greater proportions of women belonging to the charismatic faith would support their partners choice of vasectomy as a contraceptive option compared to the other religious faiths. The charismatic churches that were generally formed out of the orthodox churches. ${ }^{15,16}$ and may have relatively younger members are more liberal, flexible and receptive to modern family planning methods, including vasectomy, compared to Orthodox Church members who are relatively older and tend to have stronger views about family planning. ${ }^{15,16}$

\section{CONCLUSION}

Although, awareness of vasectomy was found to be low, the study demonstrated the preference of women to have their partners opt for vasectomy rather than them going for BTL. This was mainly influenced by their ethnicity, previous contraceptive use and awareness of vasectomy. Also, their willingness to support their partner's decision to use vasectomy as a male method of modern contraception was influenced by their age, duration of marriage and religion.

To improve on women's support for uptake of vasectomy among men, there should be efforts to increase the awareness of vasectomy among women. Also, there is the need to increase awareness of contraceptive methods and their usage as a precursor for supporting vasectomy among couples through various forms of mass media campaigns. These campaigns could use satisfied users to convey messages on the benefits of vasectomy as a means of assuaging the fears and misconception militating against the adoption of the practice.

\section{REFERENCES}

1. Cleland J, Bernstein S, Ezeh A, Faundes A, Glasier A, Innis J. Family planning: the unfinished agenda. The Lancet. 2006 Nov 18;368(9549):1810-27.

2. United Nations, Department of Economic and Social Affairs (UNDESA), Population Division. Trends in Contraceptive Use Worldwide 2015 (ST/ESA/SER.A/349) 
http://www.un.org/en/development/desa/population/publications/pdf/family/trendsContraceptiveUse2015Report.pdf. Accessed 23 ${ }^{\text {rd }}$ Oct 2016.

3. Saoji A, Hajare S, Deoke A. Awareness and perception of vasectomy among women attending antenatal clinic at Teaching Hospital, Nagpur, India. Int J Biol Med Res. 2012;3(4):2401-4.

4. Steiner MJ, Dalebout S, Condon S, Dominik R, Trussell J. Understanding risk: a randomized controlled trial of communicating contraceptive effectiveness. Obstet \& Gynecol. 2003 Oct 1;102(4):70917.

5. Chiou CF, Trussell J, Reyes E, Knight K, Wallace J, Udani J, Oda K, Borenstein J. Economic analysis of contraceptives for women. Contracept. $2003 \mathrm{Jul}$ 1;68(1):3-10.

6. Bunce A, Guest G, Searing H, Frajzyngier V, Riwa P, Kanama J, Achwal I. Factors affecting vasectomy acceptability in Tanzania. Int Fam Plan Perspect. 2007 Mar 1:13-21.

7. Shih G, Turok DK, Parker WJ. Vasectomy: the other (better) form of sterilization. Contracept. $2011 \mathrm{Apr}$ $1 ; 83(4): 310-5$.

8. Ghana Statistical Service (GSS), Ghana Health Service (GHS), and ICF International. Ghana Demographic and Health Survey 2014. Rockville, Maryland, USA: GSS, GHS, and ICF International; 2015.

9. Ghana Statistical Service (GSS), Ghana Health Service (GHS), and Macro International. Ghana Demographic and Health Survey 2008. Calverton Maryland, USA: GSS, GHS, and Macro International; 2009.

10. Adongo PB, Tapsoba P, Phillips JF, Tabong PT, Stone A, Kuffour E, Esantsi SF, Akweongo P. "If you do vasectomy and come back here weak, I will divorce you": a qualitative study of community perceptions about vasectomy in Southern Ghana. BMC Int Health and Human Rights. 2014 Dec;14(1):16. http://doi.org/10.1186/1472-698X-14-16

11. Pile JM. Vasectomy advocacy package: Safe, costeffective, and underutilized. Advocacy Brief 2008; New York: Engender Health/The ACQUIRE Project

12. Kols A, Lande R. Vasectomy: Reaching out to new users. Population Reports, Series D, No. 6. Baltimore, MD: INFO Project, Johns Hopkins Bloomberg School of Public Health, 2008. http://www.infoforhealth.org/pr/d6/d6.pdf. Accessed 30 ${ }^{\text {th }}$ Sep 2016.

13. Ghana Health Service, Central Region. http://www.ghanahealthservice.org/rhdcategory.php?ghsrid=5\&cid $=23$. Accessed $23^{\text {rd }}$ Oct 2018.

14. International Institute for Population Sciences (IIPS) and Macro International. (2007) National Family Health Survey (NFHS-3), 2005-06: India: Volume I. Mumbai: IIPS. http://pdf.usaid.gov/pdf_docs/PNADK385.pdf. Accessed 30 $0^{\text {th }}$ Sep 2016

15. das Dores Campos Machado M. Sexual values and family planning among charismatic and Pentecostal movements in Brazil. Reprode Health Matters. 1996 Jan 1;4(8):77-85.

16. A Report by the World Faiths Development Dialogue with Support from the United Nations Foundation, Universal Access Project. Faith And international Family planning 2014

https://s3.amazonaws.com/berkleycenter/140201WFDDFaithandInternationalFamilyPlanningReportPdf. Accessed 29 $9^{\text {th }}$ Jan 2018 